\title{
The effect of ear acupressure (auriculotherapy) on sexual function of lactating women: protocol of a randomized sham controlled trial
}

\author{
Sanaz Barghamadi ${ }^{1}$, Zainab Alimoardi ${ }^{2}$, Terry Oleson ${ }^{3}$ and Nasim Bahrami ${ }^{2^{*}}$ (D)
}

\begin{abstract}
Background: Lactation has a negative effect on female sexual function. Hormonal changes during lactation cause changes which might lead to dyspareunia, lack of libido, and anorgasmia. There are various pharmacological and non-pharmacological approaches to treat sexual dysfunction. While pharmacological treatment has multiple unwanted side effects, non-pharmacological therapies such as complementary medicine are a potential safer alternative. The aim of this study is to evaluate the effect of ear acupressure on sexual function of lactating women.

Methods/design: This is a randomized clinical trial with a parallel sham control group. In this study, 76 lactating women between 6 months and 1 year after childbirth were referred to health care centers in Qazvin City and would be invited to participate. Participants will be divided into intervention $(n=38)$ and control $(n=38)$ groups using simple block randomization. Both intervention and sham control groups will be visited over 10 sessions within a 4-day interval. At each visit, the adhesives containing Vaccaria seed will be adhered for the intervention group, while non-latex-based adhesives with no Vaccaria seeds will be placed on the same ear acupoints for the sham control group. Selected ear acupoints include genitalia (two ear points), pelvic point, master shoulder, and posterior pituitary gland. The women will be asked to hold the seeds on their ears for 3 days and press each ear point three times a day for $20 \mathrm{~s}$. After 3 days, they will be asked to remove the seeds from their ears and rest for 1 day. Sexual function as primary outcome in both groups will be assessed using the Female Sexual Function Index before and immediately after 1 and 2 months after the intervention. Also, Sexual Quality of Life as secondary outcome will be assessed using Sexual Quality of Life-Female (SQOL-F) before and 2 months after intervention. Data will be analyzed using repeated measure ANOVA at the significant level of 0.05 .
\end{abstract}

Discussion: This study is expected to support the impact of ear channel ear acupressure on sexual function in lactating women.

Trial registration: Iranian Clinical Trial Registration Center IRCT20190626044028N1. Registered on 16 August 2019

Keywords: Ear acupressure, Sexual function, Lactation

\footnotetext{
* Correspondence: nbahrami@qums.ac.ir

${ }^{2}$ Social Determinants of Health Research Center, Research Institute for

Prevention of Non-Communicable Diseases, Qazvin University of Medical

Sciences, Shahid Bahonar Blvd, Qazvin, Iran

Full list of author information is available at the end of the article
}

(c) The Author(s). 2020 Open Access This article is licensed under a Creative Commons Attribution 4.0 International License, which permits use, sharing, adaptation, distribution and reproduction in any medium or format, as long as you give appropriate credit to the original author(s) and the source, provide a link to the Creative Commons licence, and indicate if changes were made. The images or other third party material in this article are included in the article's Creative Commons licence, unless indicated otherwise in a credit line to the material. If material is not included in the article's Creative Commons licence and your intended use is not permitted by statutory regulation or exceeds the permitted use, you will need to obtain permission directly from the copyright holder. To view a copy of this licence, visit http://creativecommons.org/licenses/by/4.0/. The Creative Commons Public Domain Dedication waiver (http://creativecommons.org/publicdomain/zero/1.0/) applies to the data made available in this article, unless otherwise stated in a credit line to the data. 


\section{Background}

The post-childbearing period is a crucial stage in the woman's life that involves physical, hormonal, mental, social, and cultural changes [1]. Fatigue, insomnia, some stressors such as child care, and changes in the body image along with hormonal changes can reduce interest in sexual life and decrease the number of sexual intercourses during this period [1]. Endocrine function of lactation has a negative effect on sexual function, because prolactin decreases sexual hormones such as androgen and estrogen. This mechanism reduces sexual function because of vaginal dryness, vaginal epithelium atrophy, and dyspareunia [2]. About two thirds of women during lactating period experience at least one sexual problem, such as decreased libido, lack of sexual pleasure, dyspareunia, and vaginal dryness, which usually are resolved within 1 year after childbirth [3, 4]. The prevalence of sexual dysfunction increases from 19 to $63 \%$ in the prepartum period [5] to 34 to $91 \%$ in the postpartum period [6]. The results of various Iranian studies confirmed the high prevalence (31.5 to $85.4 \%$ ) of sexual dysfunction during lactation $[7,8]$. Therefore, sexual dysfunction is a common problem during lactation that needs more attention from health care providers.

In the post-childbearing period, most women try to return to their sexual life within 8 to 12 weeks after childbirth. However, it may take up to 1 year to resume sexual relationships with the same quality of before pregnancy [9]. Psychotherapy and pharmacotherapy are two main methods for treating female sexual dysfunction (FSD) [10]. However, the US Food and Drug Administration (FDA) does not recommend any foods or medicines for the treatment of FSD [11]. Therefore, nonpharmacological therapies such as complementary medicine are a potentially safer alternative to pharmacological therapy. Acupressure is one of the non-invasive complementary methods of traditional Chinese medicine (TCM) based on the principles of acupuncture [12]. Acupuncture stimulates medical points and meridians that are distributed throughout the body to regulate physiologic reactions [13]. Acupressure, like acupuncture, modulates a person's vital energy by stimulating acupoints and meridians that are distributed throughout the body [14].

The external ear is one of the several somatotopic microsystems that can be used in acupressure. Ear acupressure, also known as auriculotherapy or auricular acupressure $[15,16]$, was first presented in ancient Chinese medicine (300 to 500 years BC), but Dr. Paul Nogier was the first Western physician who put forward auriculotherapy in a scientific way $[13,17,18]$. According to this theory, each part of the body is associated with a specific part of the ear that reflects the physiological or pathological state of the body [13]. In this method, the outer surface of the ear (auricle) can be stimulated to reduce pathological conditions in other parts of the body [13]. Ear stimulation can be performed in various ways such as manual finger pressure, electrical stimulation, lasers, different types of needles, magnetic seeds, and seeds to strengthen neural connections [18]. The World Health Organization (WHO) has recognized ear acupuncture as a promising therapeutic approach, because of its efficacy in managing health disorders [15]. Ear acupuncture has been recognized as a form of acupuncture that can affect all body organs [19]. Ear acupressure is an easy, non-invasive, and safe therapy [20,21]. It is easy to use for mothers who need to take care of their child in the post-childbearing period [13].

There are several studies supporting the effects of ear acupressure on insomnia [20,22], menstrual cramps and dysmenorrhea $[21,23,24]$, premenstrual pain [25], chemotherapy-induced nausea and vomiting [26], smoking cessation [27], obesity [18], and shortness of breath [28]. However, the effect of ear acupressure on sexual function has not been studied.

\section{Research aim}

This study is designed to investigate the effect of ear acupressure on the sexual function of lactating women.

\section{Methods}

\section{Design and setting}

This is a randomized clinical trial with a parallel sham controlled group. The study is designed in accordance with the CONSORT standards. Lactating women referred to health care centers in Qazvin City, Iran, will be invited to participate. Figure 1 shows the CONSORT flow diagram. The current protocol is organized based on the SPIRIT-TCM extension [29].

\section{Participants}

In this study, breastfeeding women between 6 months and 1 year after childbirth will be referred to health care centers in Qazvin City, Iran, and they will be invited to participate in the study. Inclusion criteria will be willingness to participate in the study, being literate, being primiparous, breastfeeding, full-term singleton delivery, lesion-free auricle, no ulcer and pain in the ear, and ability to present for all intervention sessions. Exclusion criteria will be being away from their spouse for more than 1 month, having complications during pregnancy, or having postpartum depression in the post-childbearing period. These criteria were diagnosed using the Edinburgh Postpartum Depression Scale, substance abuse in the individual or the spouse, and history of illnesses affecting sexual function in a woman or her spouse (e.g., premature ejaculation, cardiovascular, mental health disorders, thyroid diseases, any form of cancer, or injuries 


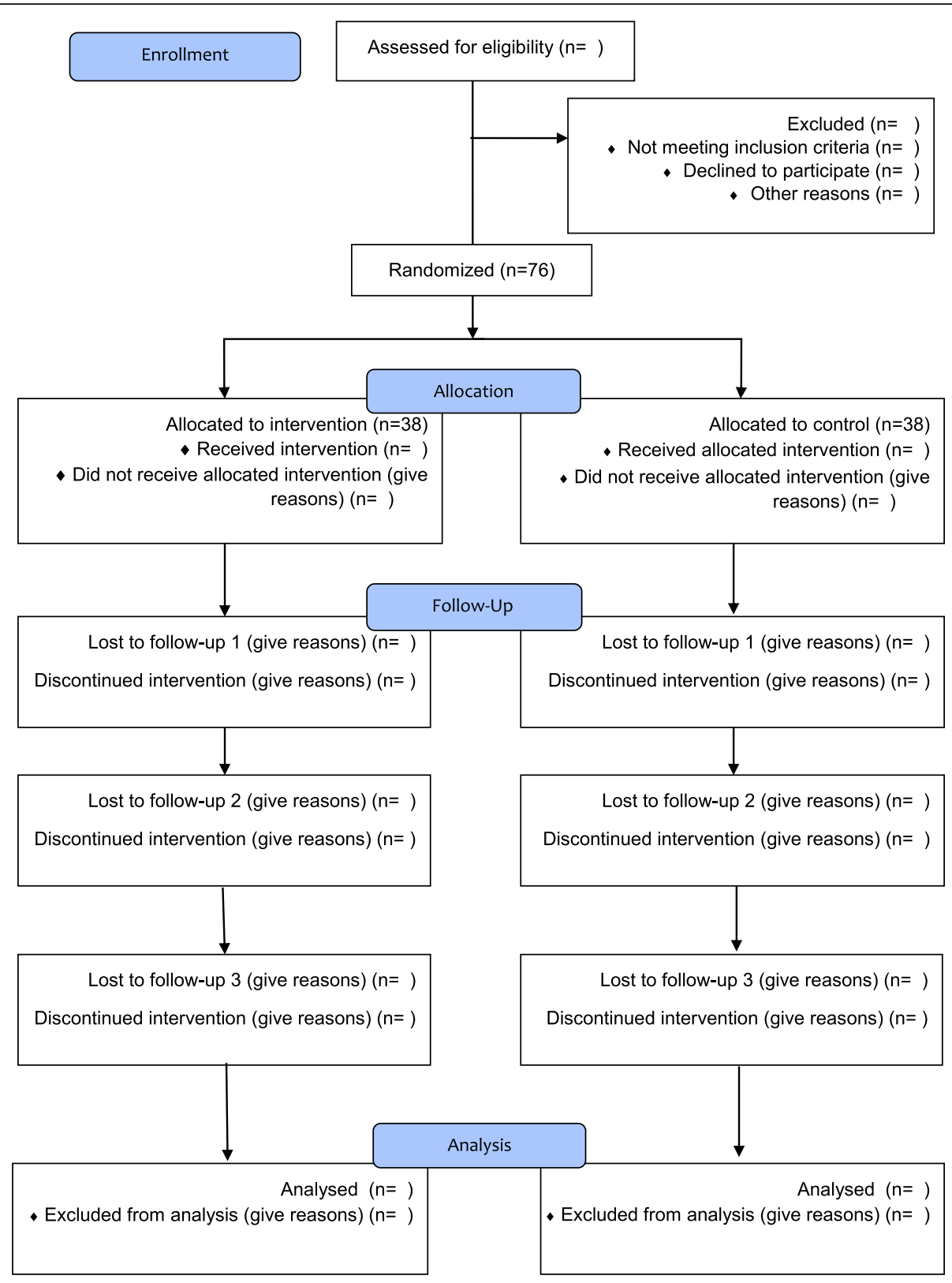

Fig. 1 The CONSORT flow diagram

of the genital area). The use of drugs affecting sexual function such as psychotropic, cardiovascular, neurological, and hormonal drugs will also be excluded. After the initial screening, the Demographic and Obstetric Questionnaire and Female Sexual Function Index (FSFI) will be completed by the participants before any intervention.

\section{Role and qualification of practitioners}

The research team consists of one specialist in auriculotherapy (TO), two specialists in reproductive health (ZA and NB), and one midwifery postgraduate student. The protocol of intervention was designed based on the literature review and expert opinion of $\mathrm{TO}$ who is an expert in auriculotherapy and is a journal editor for several international journals. Other team members have been qualified in this technique before designing present research. Participant screening and care providing will be done by $\mathrm{SB}$, and ZA and $\mathrm{NB}$ will monitor her during the first 10 sessions to ensure the fidelity of providing intervention.

\section{Sample size calculation}

Sample size is estimated according to the study of Bokaie et al. with the mean and standard deviation of 
total sexual function score has been reported as $24.65 \pm$ 3.47 and $22.27 \pm 3.03$ in the intervention (telephone counseling group) and control groups, respectively [30]. Therefore, considering the first type error $(\alpha)=0.05$ (95\% confidence), the second type error $(\beta)=0.2(80 \%$ power) and error $d=5$, and the possibility of $10 \%$ loss to follow-up, 38 individuals for each group are required. So, the total sample size will be 76 people.

\section{Intervention}

\section{Ear acupressure group}

The researcher will clean the auricle using $75 \%$ alcohol and then place Vaccaria seeds using non-latex-based adhesives on ear acupoints for genitalia, pelvis, shoulder, and the posterior pituitary gland. Figure 2 illustrates the intended ear acupoints. Intervention is designed for 10 sessions within a 4-day interval. During these sessions, the seeds are placed on the designated ear acupressure points. The women will be instructed to keep the seeds on their ears for 3 days, during which each point should be compressed three times a day for $20 \mathrm{~s}$. The compression should be performed with moderate stimulation through pressing steadily and slightly tighter until feeling a slight tingling and discomfort. After 3 days, they will be asked to remove the seeds from their ears and rest for a day [29]. The women will be reminded daily by sending the text and will be reminded by phone for the next interventional session. This procedure will be performed for ten sessions for each participant. It should be noted that if a participant has problems during the use of the method for any reason (displacement of seeds, discomfort, etc.), she can remove the previous seed and ask the researcher to re-attach new seeds.

\section{Sham control group}

The control group will have sessions that will be the same as the intervention group except that no Vaccaria seeds will be placed on the ear acupoints.

\section{Measures}

In this study, four measures will be used for data collection.

\section{Demographic and Obstetric Questionnaire}

The demographic section includes questions such as age, education level, occupation, place of residence, economic status, age at marriage, and length of marriage. The obstetric section includes questions regarding the number of pregnancies, type of contraceptive method, delivery date, type of delivery, perineal injury, instrumental delivery, history of painful intercourse in prenatal period, infant gender, birth weight, first lactation, number of intercourse per month before pregnancy, onset of first intercourse after delivery, and average number of intercourses per week during lactation. Validity of this questionnaire will be confirmed by some of the faculty members of the midwifery department of Qazvin University of Medical Sciences, Iran.

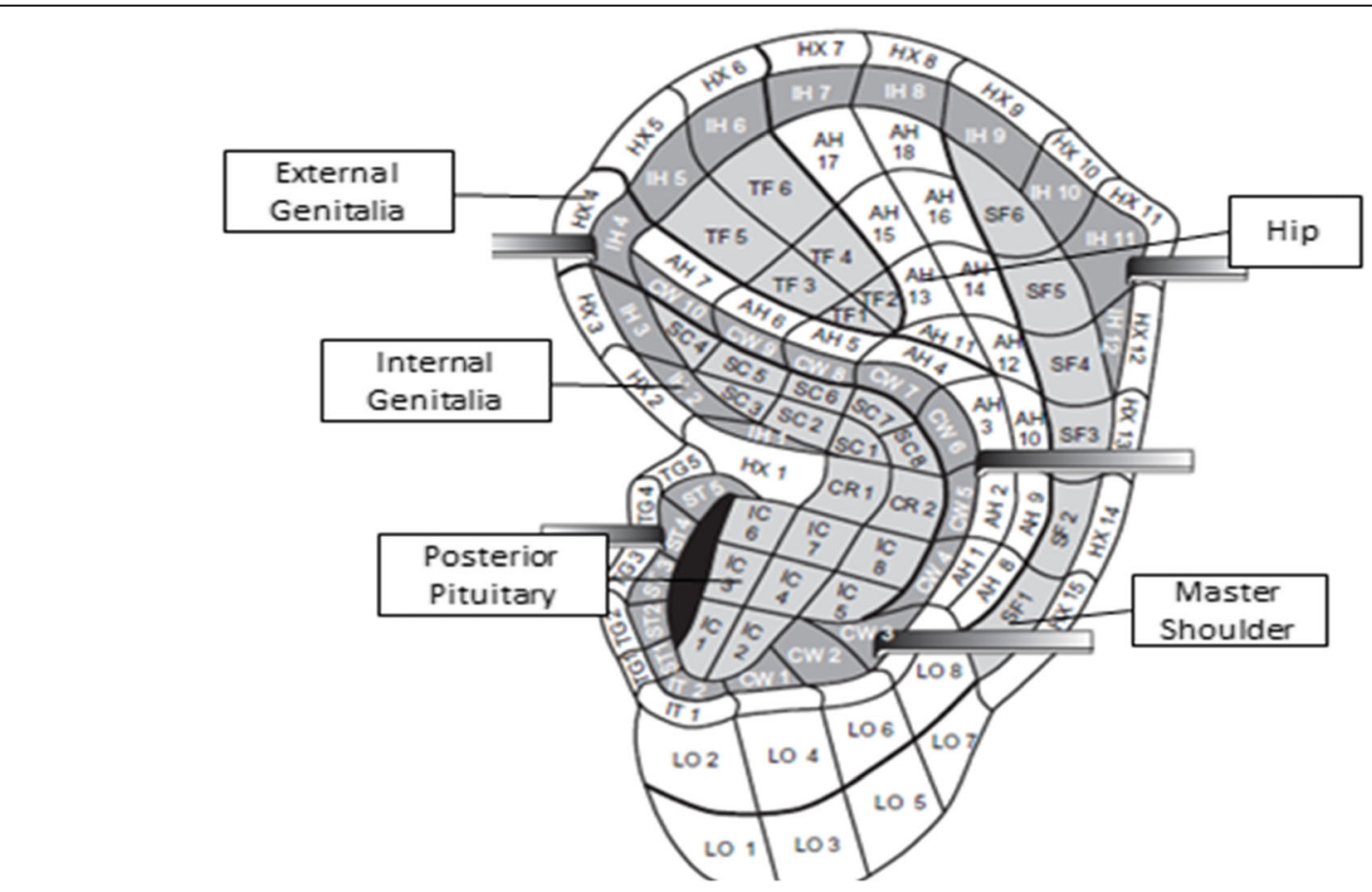

Fig. 2 The selected ear acupoints 


\section{Female Sexual Function Index (FSFI)}

It has been designed by Rosen et al. to evaluate sexual function in women over the past 4 weeks [31]. It consists of 19 items subdivided into six subcategories of sex desire (2 items), arousal (4 items), lubrication (4 items), orgasm (3 items), satisfaction (3 items), and pain (3 items). These subcategories have response ranges from 0 or 1 to 5 , with higher scores indicating better sexual performance [32]. The questionnaire has been used in many studies abroad and has shown to have a high degree of internal consistency, reliability, and validity [33]. The findings of Fakhri and Mohammadi's study showed that the Farsi version of FSFI, FSFI-IV, is a reliable and valid instrument with appropriate psychometric properties to evaluate women's sexual function [32, 34]. Reliability of the scale has been calculated through stability analysis or calculation of the internal consistency coefficient. The Cronbach's alpha coefficient was 0.70 and was higher for all domains and for the whole scale [34]. In addition, reliability was confirmed by the test-retest method and the correlation coefficient was reported high indicating that FSFI-IV is reusable within a 4-week interval [31, 35-38]. The maximum score for each domain is 6 and for the whole scale is 36 . Also, any score less than 28 will be used to indicate sexual dysfunction [34].

\section{The Edinburgh Postpartum Depression Rating Scale}

This 10-item scale has been designed to detect depression from 6 weeks after delivery. The Edinburgh Scale scores vary between 0 and 30 with cutoff point 12 and above to detect postpartum depression [39]. Psychometric evaluation of the Farsi version of this scale is carried out in 2015 [40]. The Cronbach's alpha for the Edinburgh Scale has been reported as 0.7. Validity of the Edinburgh Beck Scale has been reported as 0.44. The findings of the study confirmed the high validity of the Farsi version of the Edinburgh Scale for the diagnosis of postpartum depression [40].

\section{The Sexual Quality of Life-Female (SQOL-F)}

It is a short tool that specifically assesses the relationship between sexual function and women's quality of life. It has been developed by Symonds et al. [41]. This 18-item questionnaire focuses on sexual self-esteem, emotional affairs, and relationships. Each item is responded with a Likert scale of strongly agree (score 6) to strongly disagree (score 1). Higher scores indicate better quality of sexual life for women [41]. Validity and reliability of the Farsi version of this scale have been confirmed by Maasoumi et al. [42].

\section{Primary outcome}

Primary outcome of this study is to investigate changes of sexual function using the FSFI.

\section{Secondary outcome}

The secondary endpoint is investigating the quality of women's sexual life, which will be assessed using the Sexual Quality of Life Questionnaire. Any harm or side effects will be also reported.

\section{Study procedure}

After obtaining the necessary permissions from the Ethics Committee of Qazvin University of Medical Sciences, registration at the Iranian Clinical Trial Registration Center (IRCT), and obtaining the permission from Qazvin Nursing and Midwifery School, the researcher will attend for recruitment in Qazvin Health Centers. The lactating women of each center will be invited for participation. The process and purpose of the research will be explained to those who meet the inclusion criteria. Also, they will be ensured that their information will be kept confidential and that the questionnaires will be anonymous and coded in accordance with the research ethics. They will enter into the study after signing the written consent form. The researcher will ensure that they can leave the study at any time. After enrolling eligible individuals, a simple block randomization will be used. Participants will be randomly assigned to the intervention and control groups.

The questionnaires will be filled out by the participants before the intervention. Then, the intervention (acupressure) will be performed as mentioned above. Evaluation of sexual function in both the intervention and control groups will be performed using the FSFI questionnaire immediately, 1 and 2 months after the intervention. Figure 3 provides the timeline of recruitment, allocation, and assessment.

\section{Statistical analysis}

Data will be analyzed using the chi-square test, Fisher exact test, and independent $t$ test via the SPSS v.24 software. The Kolmogorov-Smirnov and Shapiro tests will also be used to check for the normal distribution of sexual function scores. Descriptive statistics (number, mean, and standard deviation) will be used to describe the demographic characteristics of the participants. The repeated measure ANOVA will be used to compare the mean sexual function of women before and after the intervention. The significance level of all tests is set as $p<0.05$.

\section{Methods to protect against bias Randomization and allocation}

Sampling will be made using a two-step sampling method. In the first step, Qazvin City will be considered as five geographical districts. Next, two health centers will be randomly selected in each of these five districts of Qazvin City. Secondly, women referred to selected 


\begin{tabular}{|c|c|c|c|c|c|c|c|c|c|c|c|c|c|c|c|}
\hline STUDY PERIOD & Enrolment & Allocation & \multicolumn{10}{|c|}{ Post-allocation } & \multicolumn{3}{|c|}{ Close-out } \\
\hline TIMEPOINT & $-t_{1}$ & 0 & $t_{1}$ & $t_{2}$ & $t_{3}$ & $t_{4}$ & $t_{5}$ & $t_{6}$ & $t_{7}$ & $t_{8}$ & $t_{9}$ & $t_{10}$ & $t_{11}$ & $t_{12}$ & $t_{13}$ \\
\hline \multicolumn{16}{|l|}{ ENROLLMENT: } \\
\hline Eligibility screen & $x$ & & & & & & & & & & & & & & \\
\hline \multirow{2}{*}{$\begin{array}{l}\text { Informed consent } \\
\text { Randomized by } \\
\text { independent person }\end{array}$} & $\mathrm{X}$ & & & & & & & & & & & & & & \\
\hline & $x$ & & & & & & & & & & & & & & \\
\hline Allocation & & $x$ & & & & & & & & & & & & & \\
\hline \multicolumn{16}{|l|}{ INTERVENTIONS: } \\
\hline \multicolumn{16}{|l|}{$\begin{array}{c}\text { Group A: Auricular } \\
\text { acupressure }\end{array}$} \\
\hline & & & & & & & & & & & & & & & \\
\hline \multicolumn{16}{|l|}{ Group B: Control } \\
\hline \multicolumn{16}{|l|}{ ASSESSMENTS: } \\
\hline FSFI & $x$ & & & & & & & & & & & & $x$ & $x$ & $x$ \\
\hline$S-Q O L$ & $\mathrm{x}$ & & & & & & & & & & & & & & $x$ \\
\hline EPDS & $\mathrm{X}$ & & & & & & & & & & & & & & \\
\hline
\end{tabular}

Fig. 3 schedule of enrolment, interventions, and assessments

health centers will be assessed for eligibility and, in case of willingness to participate in the study, will be recruited. They will be randomly assigned to two groups as follows: One letter is assigned to each group (A: intervention group, B: control group), and all possible conditions for the 4-block will be written and numbered, as follows: 1.AABB 2.ABAB 3.BBAA 4.BABA 5.ABBA 6.BAAB 7.

In a simple block randomization method (using the table of random numbers), numbers of blocks will be selected until the specified sample size is achieved. The random allocation sequence is specified. For example, if the numbers given are $3,2,2,1$, and ..., respectively, the allocation sequence will be as follows: $A A B B A B A B$ ABAB BBAA. As a result, each participant will have a unique code $(n=76)$.

\section{Allocation concealment}

For this purpose, after preparing the allocation sequence, the sequence is annotated on paper and placed in opaque sealed envelopes, which will be numbered consecutively. The questionnaires will be coded in the same manner. A questionnaire with the same code will be completed by the person who receives code 1 intervention. The assignment sequence and its concealment will be performed by someone outside the research team.

\section{Blinding}

Participants, outcome assessor, and statistical analyzer will be blind to which group a participant was placed. The individual entering the data from the participant questionnaires on demographic information, postpartum depression, female sexual functioning, and female quality of life will be blind to which participant was assigned to the auricular acupressure seed group or the sham control group.

\section{Treatment fidelity}

One of the researchers $(\mathrm{SB})$ is responsible to perform intervention. She has participated specific course on auriculotherapy and is supervised by acupuncturist (MHA) about how to perform the intervention. Approximately $15 \%$ of intervention sessions will be run under supervision of the acupuncturist to ensure that all acupoints are chosen correctly.

\section{Data management}

One of the researchers $(\mathrm{SB})$ will be responsible for collecting data at each study stage and will assign another individual for the task of data entry into the SPSS software. This process will be performed under supervision of NB and ZA. 


\section{Ethical and safety issues}

The research protocol will be reviewed and approved by the Ethics and Human Research Committee of Qazvin University of Medical Sciences (decree code: IR.QUMS.REC.1398.056). It is registered on the Iranian Clinical Trial Registration Center under decree code of IRCT20190626044028N1. In addition, the following ethical considerations will be considered throughout this research: obtaining written informed consent, the volunteer nature of participation in the study, ability to withdraw from the study at any time, and confidentiality of information even during the publication of findings. All ethical issues related to clinical trials will be considered. Informed consent during recruitment phase will be obtained by SB.

\section{Discussion}

To the best of our knowledge, this study is the first randomized clinical trial investigating the effect of ear acupressure on the sexual function of lactating women. The strength of this study is the randomized design with parallel treatment procedures and a large sample size, but due to the importance of the treatment practitioner knowing whether they are placing an adhesive patch with a Vaccaria seed or without one, a true double blind study is not possible. Acupressure has no known side effects, is non-invasive, and is easy to use [20, 21]. Therefore, the therapist and clients can develop a sense of closeness, trust, and confidence [20]. Several studies have shown promising results about the effect of ear acupressure on insomnia [20,22], menstrual cramps and dysmenorrhea [21, 23, 24], premenstrual pain [25], chemotherapy-induced nausea and vomiting [26], smoking cessation [27], obesity [18], and shortness of breath [28]. In the study of Oakley et al., acupuncture was affective in premenopausal women with sexual function [43]. In line with previous literature, this study would provide insights about the impact of ear acupressure on sexual function in lactating women.

\section{Abbreviations \\ CONSORT: Consolidated Standards of Reporting Trials; SQOL-F: Sexual Quality} of Life-Female

\section{Acknowledgements \\ Not any in this stage.}

\section{Trial status}

The recruitment has not yet begun, and necessary permissions are acquired; the estimated date of recruitment is November 27, 2019. The expected time for completing the recruitment is March 30, 2020. Protocol version 1 registered on August 16, 2019.

\section{Authors' contributions}

All authors (SB, ZA, NB, and TO) contributed to the design of the study. SB, $N B$, and ZA drafted the preliminary manuscript. TO revised the manuscript and prepared the final version of the manuscript. All authors revised the manuscript, agreed to be fully accountable for ensuring the integrity and accuracy of the study, and read and approved the final version of the manuscript to be published. All the authors met the criteria for authorship and listed as co-authors on the title page.

\section{Funding}

The research deputy of Qazvin University of Medical Sciences will provide financial support. Study funders have no role in the study design; the collection, management, analysis, and interpretation of data; the writing of the report; and the decision to submit the report for publication.

\section{Availability of data and materials}

Analyzed data and materials will be de-identified and published.

\section{Ethics approval and consent to participate}

Research protocol is approved by the Ethics and Human Research Committee of Qazvin University of Medical Sciences (decree code: IR.QUMS.REC.1398.056). Permissions from responsible authority will be obtained before recruitment. Informed consent will be acquired before participation.

\section{Consent for publication}

Not applicable.

\section{Competing interests}

None to declare.

\section{Author details}

${ }^{1}$ Student Research Committee, Qazvin University of Medical Sciences, Qazvin, Iran. ${ }^{2}$ Social Determinants of Health Research Center, Research Institute for Prevention of Non-Communicable Diseases, Qazvin University of Medical Sciences, Shahid Bahonar Blvd, Qazvin, Iran. ${ }^{3}$ Emperor's College of Traditional Oriental Medicine, Santa Monica, CA, USA.

Received: 16 November 2019 Accepted: 8 August 2020

Published online: 20 August 2020

\section{References}

1. Abdelhakm EM, Said AR, Elsayed DMS. Effect of PLISSIT model sexual counseling program on sexual quality of life for postpartum women. Am J Nurs Sci. 2018;7(2):63.

2. Avery MD, Duckett $L$, Frantzich $C R$. The experience of sexuality during breastfeeding among primiparous women. J Midwifery Womens Health 2000;45(3):227-37.

3. Acele EÖ, Karaçam Z. Sexual problems in women during the first postpartum year and related conditions. J Clin Nurs. 2012;21(7-8):929-37.

4. Mohammed YF, Hassan HM, Al-Dinary AM, Rashed NS. Sexual function after child birth according to the mode of delivery. AAMJ. 2014;12(4):264-84.

5. S-i H, Kumamoto $Y$, Sato $Y$, Masumori N, Horita H, Kato R, et al. Prevalence of female sexual dysfunction symptoms and its relationship to quality of life: a Japanese female cohort study. Urology. 2005;65(1):143-8.

6. Williams A, Herron-Marx S, Carolyn $H$. The prevalence of enduring postnatal perineal morbidity and its relationship to perineal trauma. Midwifery. 2007; 23(4):392-403.

7. Ahmad Shirvani M, Bagheri NM. Sexual dysfunction and related factors among breast feeding women. Iran J Obstet Gynecol Infertility. 2011;14(5): 38-44.

8. Tork Zahrani S, Banaei M, Ozgoli G, Azad M. Investigation of the postpartum female sexual dysfunction in breastfeeding women referring to healthcare centers of Bandar Abbas. Iran J Obstet Gynecol Infertility. 2016;19(35):1-12.

9. Yörük F, Karaçam Z. The effectiveness of the PLISSIT model in solving postpartum sexual problems experienced by women. Athens J Health. 2016: 3(3):235-7.

10. Davis SR, Van Der Mooren M, van Lunsen RH, Lopes P, Ribot J, Rees M, et al. Efficacy and safety of a testosterone patch for the treatment of hypoactive sexual desire disorder in surgically menopausal women: a randomized, placebo-controlled trial. Menopause. 2006;13(3):387-96.

11. Belkin ZR, Krapf JM, Goldstein AT. Drugs in early clinical development for the treatment of female sexual dysfunction. Expert Opin Investig Drugs. 2015;24(2):159-67

12. Ozgoli G, Mobarakabadi SS, Heshmat R, Majd HA, Sheikhan Z. Effect of LI4 and BL32 acupressure on labor pain and delivery outcome in the first stage 
of labor in primiparous women: a randomized controlled trial. Complement Ther Med. 2016;29:175-80.

13. Oleson T. Auriculotherapy manual: Chinese and Western systems of ear acupuncture; 2014

14. Yeh M-L, Chang Y-C, Huang Y-Y, Lee T-Y. A randomized controlled trial of auricular acupressure in heart rate variability and quality of life for hypertension. Complement Ther Med. 2015;23(2):200-9.

15. Tan J-Y, Molassiotis A, Wang T, Suen LK. Current evidence on auricular therapy for chemotherapy-induced nausea and vomiting in cancer patients: a systematic review of randomized controlled trials. Evid Based Complement Alternat Med. 2014;2014:18.

16. Yeh $\mathrm{CH}$, Chien L-C, Chiang YC, Lin SW, Huang CK, Ren D. Reduction in nausea and vomiting in children undergoing cancer chemotherapy by either appropriate or sham auricular acupuncture points with standard care. J Altern Complement Med. 2012:18(4):334-40.

17. Abbate S. Chinese auricular acupuncture. Florida: Routledge; 2016.

18. Yeh T-L, Chen H-H, Pai T-P, Liu S-J, Wu S-L, Sun F-J, et al. The effect of auricular acupoint stimulation in overweight and obese adults: a systematic review and meta-analysis of randomized controlled trials. Evid Based Complement Alternat Med. 2017;2017:16.

19. Yeh $\mathrm{CH}$, Chiang $\mathrm{YC}$, Hoffman SL, Liang Z, Klem ML, Tam WW, et al. Efficacy of auricular therapy for pain management: a systematic review and metaanalysis. Evid Based Complement Alternat Med. 2014:2014:14.

20. Kim JY, Ryu HS, Nam SH, Park KS. Effects of auricular acupressure therapy on nocturia and insomnia in the elderly. Korean J Rehabil Nurs. 2014:17(1):1-9.

21. Wang Y-J, Hsu C-C, Yeh M-L, Lin J-G. Auricular acupressure to improve menstrual pain and menstrual distress and heart rate variability for primary dysmenorrhea in youth with stress. Evid Based Complement Alternat Med. 2013:2013:8.

22. Shergis JL, Ni X, Jackson ML, Zhang AL, Guo X, Li Y, et al. A systematic review of acupuncture for sleep quality in people with insomnia. Complement Ther Med. 2016;26:11-20.

23. Dantas KKdL. Auriculoterapia chinesa com o uso de sementes de colza na dismenorreia primaria: relato de caso: Universidade Federal do Rio Grande do Norte; 2017.

24. Portman DJ, Bachmann GA, Simon JA, Group OS. Ospemifene, a novel selective estrogen receptor modulator for treating dyspareunia associated with postmenopausal vulvar and vaginal atrophy. Menopause. 2013;20(6): 623-30.

25. Oleson T, Flocco W. Randomized controlled study of premenstrual symptoms treated with ear, hand, and foot reflexology. Obstet Gynecol. 1993:82:906-11.

26. Kwon SJ, Park JS. Effects of auricular acupressure on chemotherapy-induced nausea, vomiting, and serum serotonin level. Korean J Adult Nurs. 2014; 26(3):330-40.

27. Di YM, May BH, Zhang AL, Zhou IW, Worsnop C, Xue CC. A meta-analysis of ear-acupuncture, ear-acupressure and auriculotherapy for cigarette smoking cessation. Drug Alcohol Depend. 2014;142:14-23.

28. Huang ET-Y, Di PhD YM. Acupuncture therapies for chronic obstructive pulmonary disease: a systematic review of randomized, controlled trials. Altern Ther Health Med. 2014;20(6):10.

29. Dai L, Cheng CW, Tian R, Zhong LL, Li YP, Lyu AP, et al. Standard Protocol Items for Clinical Trials with Traditional Chinese Medicine 2018: recommendations, explanation and elaboration (SPIRIT-TCM extension 2018). Chin J Integr Med. 2019;25(1):71-9.

30. Bokaie M, Hajimaghsoudi S, Dehghani A, Hosseini F. The effect of sexual health counselling on the sexual function and satisfaction of breastfeeding women in the form of group consultation and telephone consultancy. J Adv Pharm Educ Res. 2019:9(S2):191-8.

31. Rosen CB, Heiman J, Leiblum S, Meston C, Shabsigh R, Ferguson D, D'Agostino R. The Female Sexual Function Index (FSFI): a multidimensional self-report instrument for the assessment of female sexual function. J Sex Marital Ther. 2000;26(2):191-208.

32. Fakhri A, Pakpour AH, Burri A, Morshedi H, Zeidi IM. The Female Sexual Function Index: translation and validation of an Iranian version. J Sex Med. 2012;9(2):514-23.

33. Wiegel M, Meston C, Rosen R. The female sexual function index (FSFI): crossvalidation and development of clinical cutoff scores. J Sex Marital Ther. 2005;31(1):1-20.
34. Mohammadi KH, Heydari M, Faghihzadeh S. The Female Sexual Function Index (FSFI): validation of the Iranian version. Health Monit J Iran Inst Health Sci Res. 2008;7(3):0.

35. Burri A, Cherkas L, Spector T. Replication of psychometric properties of the FSFI and validation of a modified version (FSFI-LL) assessing lifelong sexual function in an unselected sample of females. J Sex Med. 2010;7(12):3929-39.

36. Sidi $\mathrm{H}$, Abdullah $\mathrm{N}$, Puteh SEW, Midin M. The female sexual function index (FSFI): validation of the Malay version. J Sex Med. 2007;4(6):1642-54.

37. Sun X, Li C, Jin L, Fan Y, Wang D. Development and validation of Chinese version of female sexual function index in a Chinese population-a pilot study. J Sex Med. 2011:8(4):1101-11.

38. Ter Kuile MM, Brauer M, Laan E. The female sexual function index (FSFI) and the female sexual distress scale (FSDS): psychometric properties within a Dutch population. J Sex Marital Ther. 2006;32(4):289-304.

39. Cox JL, Holden JM, Sagovsky R. Detection of postnatal depression: development of the 10-item Edinburgh Postnatal Depression Scale. Br J Psychiatry. 1987;150(6):782-6.

40. Ahmadi kani Golzar A, GoliZadeh Z. Validation of Edinburgh Postpartum Depression Scale (EPDS) for screening postpartum depression in Iran. J Nurs Educ. 2015;3(3):1-10

41. Symonds T, Boolell M, Quirk F. Development of a questionnaire on sexual quality of life in women. J Sex Marital Ther. 2005;31(5):385-97.

42. Maasoumi R, Lamyian M, Montazeri A, Azin SA, Aguilar-Vafaie ME, Hajizadeh $E$. The sexual quality of life-female (SQOL-F) questionnaire: translation and psychometric properties of the Iranian version. Reprod Health. 2013;10(1):25.

43. Oakley SH, Walther-Liu J, Crisp C, Pauls R. Acupuncture in premenopausal women with hypoactive sexual desire disorder: a prospective cohort pilot study. Sexual medicine. 2016:4(3):e176-e81.

\section{Publisher's Note}

Springer Nature remains neutral with regard to jurisdictional claims in published maps and institutional affiliations.

Ready to submit your research? Choose BMC and benefit from:

- fast, convenient online submission

- thorough peer review by experienced researchers in your field

- rapid publication on acceptance

- support for research data, including large and complex data types

- gold Open Access which fosters wider collaboration and increased citations

- maximum visibility for your research: over $100 \mathrm{M}$ website views per year

At BMC, research is always in progress.

Learn more biomedcentral.com/submissions 